\title{
Resonant laser assisted elastic scattering of electrons by lithium and sodium atoms
}

Eur. Phys. J. D 53, 173-177 (2009)

S.P. Purohit ${ }^{\mathrm{a}}$ and K.C. Mathur

Department of Physics and Materials Science and Engineering, Jaypee Institute of Information Technology University, A-10, Sector 62, Noida, U.P. 201 307, India

Received 19 March 2009

Published online 26 March 2009 - (C) EDP Sciences, Società Italiana di Fisica, Springer-Verlag 2009

The expression for $\mathrm{O}$ after equation (11) should read

$O=-\delta_{i r}+\exp \left(i \boldsymbol{q} \cdot \boldsymbol{r}_{1}\right)$

a e-mail: sppurohitjiit@gmail.com 